\title{
Site-Specific Traffic Loading Estimation Challenges in Structural Pavement Design Process in Qatar: A Case Study
}

\author{
Ahmad Al-Tawalbeh \\ ahmad.altawalbeh@seeroeng.com \\ Seero Engineering Consulting LLC, Doha, Qatar \\ Mohammed Sadeq \\ mohammed.sadeq@seeroeng.com \\ Seero Engineering Consulting LLC, Doha, Qatar \\ Husam Sadek \\ hsadek1@1su.edu \\ Louisiana State University, Baton Rouge, Louisiana, USA
}

\begin{abstract}
Upon the design of any pavement structure, three fundamental external design parameters have to be considered throughout the design process: the characteristics of the subgrade, traffic loads, and environmental conditions. This paper focuses on the main challenges being faced to estimate site-specific traffic loading for a pavement design due to the lack of accurate and recent traffic data. A case study for a pavement structural design process for an actual expressway project in the State of Qatar is discussed in this paper. This case study goes through traffic loading calculations inputs; the Average Daily Traffic (ADT), Truck Factor (TF), as well as Heavy Good Vehicle Percentage (HGV\%). The challenges of calculating these site-specific traffic loading inputs are discussed through investigation of the accuracy in traffic loading estimation using Qatar Strategic Transport Model (QSTM), and how the model can be incorporated in the design. Besides, limited available Wight-In-Motion (WIM) surveys have been discussed and the paper ends with the conclusion that rich availability of traffic data enhances the accuracy of the pavement structural design. It affects significantly the value engineering practice, and results in sustainable pavement sections.
\end{abstract}

Keywords: Traffic loading; Pavement structure; Design; Strategic transport model; Qatar

\section{INTRODUCTION}

The State of Qatar is witnessing dramatic boom in the infrastructure field as part of the governmental 2030 vision and for the preparation of FIFA World Cup Qatar 2022 According to Qatar Ministry of Finance (MOF) Website (2019), QR16.4 billion budget has been allocated for transportation and Infrastructure projects for Qatar in 2019. Consequently, significant improvement of Qatar's roads network has being achieved. Thousands of kilometres of flexible pavements are being designed and constructed taking into consideration value engineering practices and sustainability measures. Upon the design of any pavement structure, three fundamental external design parameters/ inputs have to be considered throughout the design process; (1) the characteristics of the subgrade layer, (2) expected traffic loads, and (3) environmental conditions. The 
accurate estimation of the traffic loading is one of the most critical factors that impact the value engineering results and should be studied extensively along with other pavement design inputs. Availability of the traffic data is dominating the accuracy of the estimated traffic load that results in over- or under-designed pavement structures on roadways. Limited traffic data - in terms of frequency and distribution - creates multiple challenges that all designers would face to come up with a project-customized pavement design. These challenges are presented in this paper and discussed with recommendations to overcome some of them for more robust and economically designed pavement sections.

This paper presents a number of design inputs related to traffic estimation that affects the design decision of the asphalt pavement structure. These inputs are; the Average Daily Traffic (ADT), Heavy Good Vehicle Percentage (HGV\%), and Truck Factor (TF). Some of these inputs are defined by following recommended parameters of national and/or international guidelines that were developed in different countries where the road network has different attributes and environmental conditions than Qatar. Having those parameters un-locally defined or refined increases the chance of uncertainty in the design process and risking the sustainability of the pavement structure by providing over- or under-designed sections. Therefore, national or international parameters are generally recommended to be used as references only during a structural pavement design practice and site-specific parameters have to be developed for each project.

To address the objective of this paper, a case study of a certain project in Qatar that went through the traffic load estimation challenges is presented with demonstrated recommendations.

\section{LITERATURE REVIEW}

In last few decades, many studies have been conducted to determine the sensitivity and traffic inputs in pavement structural design practice. The studies compared using site-specific inputs with default values of the country or state guides. Pavement Design Guidelines Interim Advice Notice 016 Ashghal (2013), recommended to use site-specific WIM if available to determine the actual Equivalent Single Axle Load Factors (ESALF). In a research was conducted in Ohio State to measure the effect of traffic load input level on mechanistic-empirical pavement design (Abbas et al., 2014), the authors recommended to use site-specific axle load spectra when available due to underestimated service life of statewide average axle load spectra. In the US State of Virginia, a study was conducted to analyze Virginia-Specific traffic data for use with mechanistic empirical pavement design guide (Smith and Diefenderfer, 2010). The study recommended using site-specific axle load spectra data for analysis of flexible pavements for users of Mechanistic-Empirical Pavement Design Guide (MEPDG). According to The Federal Highway Administration (FHWA), Traffic Monitoring Guide (TMG) recommends depending on several patterns of traffic fleet as industrial, geographic, agricultural, and commercial patterns, in parallel with

measured or estimated pattern in specific roads in order to define the group of roads based on truck weight (TMG, 2001). Since then, multiple researches and guidelines highlighted the importance of using site-specific pavement design inputs. This paper presents the challenges of implementing site-specific traffic loading inputs for pavement structural design in absence of traffic counting data based on authentic case study in Qatar. 


\section{TRAFFIC LOAD ESTIMATION CHALLENGES}

As mentioned earlier, multiple traffic loading inputs for any pavement design suffer from the risk of inaccuracy that raise couple of design challenges. These inputs are key factors in the design process and below each one of them is discussed in detail.

\subsection{Traffic Counts}

Under limited traffic count frequency and duration, getting an over- or under-designed pavement section is highly expected due to the wide range of input values that can be selected. The inputs; Average Daily Traffic (ADT), Heavy Good Vehicle Percentage (HGV\%), and Truck Factor (TF) are highly affected by the limited traffic counts. In the following subsections, each of the inputs are discussed.

\subsubsection{Average Daily Traffic (ADT)}

The Average Daily Traffic (ADT) value is a key input in the pavement design process as in other transportation engineering sub disciplines. The ADT is generally calculated from the annual traffic survey considering several periods throughout the year. As mentioned earlier, traffic surveys are conducted for only 1-2 weeks which affect the accuracy of the ADT estimation by ignoring the seasonal variation of the traffic volume in the project area.

\subsubsection{Heavy Good Vehicle Percentage (HGV\%)}

The HGV percentage is a sensitive input in any pavement design process. HGV percentage is commonly calculated based on annual traffic surveys conducted in the project location. When annual traffic surveys are not available, calculating HGV percentage from 1-2 weeks duration traffic survey adds significant risk to the accuracy of the design outcomes.

\subsubsection{Truck Factor (TF)}

The Truck Factor, which is also known as the "Damage Factor", is generally estimated based on the data collected from the Weight-In-Motion (WIM) surveys. The accuracy of the TF is risked due to the difference in heavy traffic fleet characteristics based on the project area and mobility of the roads. On the other hand, international guidelines recommend values of TF that do not necessarily reflect traffic characteristics in Qatar which witnesses heavy construction activities while the trucks loading regulations are varying based on the country. Interim Advice Notice (IAN) 016 recommends a wide range of TF values for each traffic class, which results in uncontrolled design inputs (Ashghal, 2013). The recommended values show general ranges based on international guidelines. The combined uncertainty of these traffic-related design inputs leads to an enormous risk in the pavement structure analysis and design.

\subsection{Strategic Transport Model Deficiencies}

The State of Qatar has issued the first strategic transport model in the year of 2013 (MMUP, 2013), with initial roads network and land-uses. The model was developed based on the travel forecasting theory that depends on land-use type for trip generation and land-use's attraction and production for trip distribution. The model is aimed for strategic 
decision-making and used for Measure of Effectiveness (MOE) purposes. Accordingly, the model is not accurate for estimating traffic fleet compositions and HGV volume for pavement design purposes. Moreover, the model needs to be continuously updated and disaggregated with plots' land-uses and road network upgrades for simulation that is more accurate. The strategic model considers the operational origin and destination trips from each plot in addition to public transport system trips, but not construction traffic generated due to the development of the plots.

\section{TRAFFIC LOAD ESTIMATION RECOMMENDATIONS}

The significant impact of the above-mentioned input challenges on the reliability of the designed pavement structure raises the need to propose and recommend solutions for more effective pavement design process. The following section documents the recommended approaches/methods for the mentioned inputs and discuss their impact on the design outcomes.

\subsection{Average Daily Traffic (ADT) Estimation}

In order to enhance the ADT estimation for a pavement design, Qatar Strategic Transport Model (QSTM), was found to be helpful in estimating the Peak Hour Volume (PHV) for each road link inside a project area. The PHV is used to better estimate the ADT value needed for the project area. The QSTM which was modelled using microsimulation software estimates the overall traffic fleet volume accurately based on many transport planning factors. Besides, the QSTM provides the chance to estimate the diverted traffic volume after upgrading the road network which provides a higher estimation accuracy (MMUP, 2013). In addition, the QSTM considers the variation of PHV along the same highway which facilitates providing several pavement structures for the road alignment while relying on limited number of traffic survey stations and could result in over- or under-estimated traffic load.

\subsection{Heavy Good Vehicle Percentage (HGV\%) Validation}

As mentioned earlier, the QSTM was found to be inaccurate to estimate the HGV volume and traffic fleet characteristics for pavement design purposes. However, the QSTM model can be incorporated by conducting flow bundle analysis of the main HGV generator zones like Cargo Airports, Ports, and Industrial Areas ...etc. The ratio of bundle volumes to background traffic volume was found to be very useful to estimate the $\mathrm{HGV} \%$. Accordingly, the calculated value can validate the $\mathrm{HGV} \%$ that is extracted from the traffic survey data.

In addition, the construction traffic can also be a crucial input that impacts the pavement durability if mis-measured. The construction traffic is usually considered as $5 \%$ of the ADT value based on the common practice and previous experience. However, the construction traffic can also be refined and validated during the design process. A ratio of construction traffic can be established per unit area for a specific truck class and added to the ADT for a forecasted number of years of development.

\subsection{Truck Factor (TF) Estimation}

Using the Gross Vehicle Weight (GVW) data extracted from the WIM stations, it was 
found to be the most reliable method to estimate the truck factor for a pavement design. The WIM survey represents the only authentic source to calculate the TF in Qatar while finding a weighted average TF of the project's traffic survey. Following the available WIM stations survey values provides Qatar-Specific TF values and controls the selected $\mathrm{TF}$ values to be within the 95 th percentile truck weight (Ashghal, 2012). This approach reflects to be more realistic and a reasonable range for TF values for design purposes.

\section{A CASE STUDY}

In this case study, a specific pavement design project for an expressway in Qatar was considered to examine the proposed recommended methodology for input considerations in the pavement design. Accordingly, a comparison between conventional and recommended methodology parameters is conducted. Table 1 shows a description of each methodology inputs.

Table 1: Inputs description for the conventional and recommended methods

\begin{tabular}{|l|l|l|}
\hline \multicolumn{1}{|c|}{ Methodology } & \multicolumn{1}{|c|}{ Conventional Method } & \multicolumn{1}{c|}{ Recommended Method } \\
\hline $\begin{array}{l}\text { Average Daily Traffic (ADT) in the } \\
\text { opening year }\end{array}$ & $\begin{array}{l}\text { Calculated based on 1-2 weeks traffic } \\
\text { survey inside the project area }\end{array}$ & $\begin{array}{l}\text { Calculated based on PHV extracted from } \\
\text { updated QSTM and Peak Hour Factor } \\
\text { (PHF) calculated based on one-week traffic } \\
\text { survey inside the project }\end{array}$ \\
\hline Truck Factor (TF) & $\begin{array}{l}\text { Commonly taken directly as average } \\
\text { values from guidelines }\end{array}$ & $\begin{array}{l}\text { Calculated based on 95th percentile TF of } \\
\text { WIM survey conducted in several stations } \\
\text { along Qatar and applied to project traffic } \\
\text { survey volume to calculate weighted } \\
\text { average TF }\end{array}$ \\
\hline $\begin{array}{l}\text { Heavy Good Vehicle (HGV) } \\
\text { Percentage }\end{array}$ & $\begin{array}{l}\text { Calculated based on HGV\% of } \\
\text { available traffic survey inside project } \\
\text { location without validation }\end{array}$ & $\begin{array}{l}\text { Calculated based on traffic survey on } \\
\text { similar attributes road and validated based } \\
\text { on QSTM flow bundle analysis of main } \\
\text { HGV generator zones in Qatar }\end{array}$ \\
\hline
\end{tabular}

Based on inputs description shown in Table 1, the pavement design parameters are listed in Table 2.

Table 2 Conventional and recommended method input values of an expressway project

\begin{tabular}{|c|c|c|c|}
\hline \multicolumn{2}{|c|}{$\begin{array}{ll}\text { Input } & \text { Methodology } \\
\end{array}$} & Conventional Method & Recommended Method \\
\hline \multicolumn{2}{|c|}{ Average Daily Traffic (ADT) in the opening year (veh/day) } & 84,000 & $53,000-79,000$ \\
\hline \multirow{6}{*}{ Truck Factor (TF) } & Class 4 & 2.85 & 1.13 \\
\hline & Class 6 & 3.75 & 1.13 \\
\hline & Class 7 & 3.25 & 0.93 \\
\hline & Class 8 & 4.95 & 0.54 \\
\hline & Class 9 & 4.63 & 0.57 \\
\hline & Class 10 & 5.13 & 0.62 \\
\hline \multicolumn{2}{|c|}{ Heavy Good Vehicle (HGV) Percentage } & 8.20 & 9.00 \\
\hline
\end{tabular}

As shown in the Table 2, it can be noticed that the ADT estimation got reduced by considering the PHV extracted from updated QSTM. Moreover, due to the fact that QSTM provides data in several locations, the calculated ADT in Table 2 shows the ranging value that covers the alignments of the studied roads/links. On the other hand, the $\mathrm{TF}$ also shows significant difference between both methods which can highly impact 
the Equivalent Single Axle Loads (ESALs) calculations (AASHTO, 1993). Finally, the HGV percentage showed higher value than the conventional method since it was estimated and validated by using the QSTM and flow bundle analysis. After fixing the values of Growth Factor (GF) and Lane Distribution Factor (LF), the traffic load in terms of ESALs has been calculated. It is found that using the conventional methodology resulted in higher traffic load up to $88 \%$ than the recommended method. One the other hand, it was found that using the conventional method with 95th percentile WIM TFs resulted in higher traffic load up to $36 \%$ than the recommended methodology.

The above-mentioned recommendations can lead to more refined design parameters taking into consideration site-specific inputs. The recommended method also represents a validation procedure to justify the selected design inputs and ensure that the final pavement section is not over- or under-designed. The accuracy of pavement design inputs translated in sustainability terms to material resources saving, cost reduction, and longer design life.

\section{CONCLUSION}

The study presents the main challenges related to the traffic loading estimation that pavement designers are facing in Qatar. The study also recommends few practical solutions to be adopted for more accurate design outcomes. The most crucial design parameters were discussed in the paper and their impact on the final design parameters was shown as a case study. Below are the main findings and conclusions of the study:

- The use of the QSTM and data collected from the WIM stations would positively affect the design inputs and refine them for more economical design thicknesses. It was found that using TF values extracted from WIM surveys along with ADT calculated based on QSTM resulted in traffic load reduction up to $88 \%$ in this case study. This reduction is changing whole considerations of the pavement design and decision making during the cost estimation of the projects.

- The use of the QSTM can validate HGV\% from traffic survey by conducting flow bundle analysis for zones that generate heavy trucks. The validation empowers certainty in the pavement design process and ensures the reliability of the selected asphalt materials and pavement layers' thicknesses.

- The case study also recommends considering site-specific traffic data when available due to significant impact on sustainability and durability of the pavement structure.

\section{REFERENCES}

AASHTO, (1993). Guide for Design of Pavement Structures (1993 AASHTO Guide). American Association of State Highway and Transportation Officials. Washington, D.C., United States.

Abbas, A. R., Frankhouser, A. \& Papagiannakis A. T., (2014). Effect of Traffic Load Input Level on Mechanistic-Empirical Pavement Design. Transportation Research Record: Journal of the Transportation Research Board, 2443, 63-77.

Ashghal (2013). Pavement Design Guidelines Interim Advice Notice 016. Revision A1. State of Qatar Public Works Authority: Doha, Qatar.

Ashghal (2012). Pavement Design Guidelines Interim Advice Notice 101. Revision 2. State of 
Qatar Public Works Authority: Doha, Qatar.

Federal Highway Administration (FHWA) (2001). Traffic Management Guide (TMG). Department of Transportation, United States.

Ministry of Municipality and Urban Planning (MMUP) (2011). Guidelines and Procedure for Transport Studies, Revision 3. Transportation and Infrastructure Planning Department; State of Qatar: Doha, Qatar.

Ministry of Finance (MOF) website (2019). https://www.mof.gov.qa/en/Pages/Data2019.aspx. Ministry of Finance, Qatar.

Smith B. C. \& Diefenderfer B. K. (2010). Analysis of Virginia-Specific Traffic Data for Use with Mechanistic-Empirical Pavement Design Guide. Transportation Research Record: Journal of the Transportation Research Board, 2154, 100-107. 